\title{
Cyclic Furnace Testing and Life Predictions of Thermal Barrier Coating Spallation Subject to a Step Change in Temperature or in Cycle Duration
}

\author{
Nirav V. Patel ${ }^{\mathrm{a}}$, Eric H. Jordan ${ }^{\mathrm{a}}$, Swetha Sridharan ${ }^{\mathrm{b}}$, Maurice Gell ${ }^{\mathrm{c}}$ \\ ${ }^{\text {a }}$ Department of Mechanical Engineering, University of Connecticut, Storrs, CT 06269-3139 \\ ${ }^{\mathrm{b}}$ Intel Corporation, Chandler, AZ 85226 \\ ${ }^{c}$ Materials Science \& Engineering, University of Connecticut, Storrs, CT 06269-3136 \\ *Corresponding author email: Jordan@engr.uconn.edu \\ Phone: $+1-860-486-5934$ \\ Fax: $+1-860-486-5088$
}




\begin{abstract}
Thermal barrier coatings (TBC), used for thermal protection of gas turbine hot section parts in service are typically subjected to thermal histories that involve variations in both maximum temperature and hold time. The primary purpose of this work is to begin to study the durability consequences of non-constant thermal exposure and the associated life prediction challenges that such load histories present. Nearly all published TBC cyclic furnace tests have been conducted at constant temperature and constant cycle duration. In this work, two types of non-constant condition tests were run, tests in which the temperature was changed part way through the cyclic life and a second type of test where the high temperature hold time was changed part way through the cycle life. The validity of the linear damage rule was examined and found to work well for changes in maximum temperature and not as well for changes in cycle duration. In addition, the stresses in the thermally grown oxide (TGO) were recorded with the use of photoluminescence piezospectroscopy (PLPS) and the changes in stress were used to predict remaining cyclic life for non-constant condition tests.
\end{abstract}

\title{
Keywords
}

Thermal barrier coatings; cyclic life prediction; cycling history effects, linear damage rule

\author{
Abbreviations \\ Thermal barrier coating (TBC) \\ Thermally grown oxide (TGO) \\ Photoluminescence piezospectroscopy (PLPS) \\ Yttria stabilized Zirconia (YSZ) \\ Electron beam physical vapor deposition (EB-PVD) \\ Gigapascal (GPa)
}




\section{Introduction}

Thermal barrier coatings (TBC) were developed to insulate the surface of superalloys to allow gas turbine engines to operate at higher temperatures with increased efficiency and durability. The ceramic-based coatings insulate the superalloy from the gas path and provide a temperature difference across the coating as much as $175^{\circ} \mathrm{C}[1]$. Most production thermal barrier coatings consist of an yttria stabilized zirconia (YSZ) ceramic top coat, and an oxidation resistant bond coat on top of a superalloy base metal.

Many previous studies of the cyclic furnace durability of TBC systems have been carried out, including those on TBC specimens similar to those used in this study [2-4]. In virtually all of these studies, the temperature and cycle duration were held constant. It is not unusual in commercial aviation that an aircraft can be used on routes of different durations both from year to year or even on a single multi-destination flight. Military aircraft engines have even more varied operational history. The traditional method for dealing with non-constant conditions in durability estimation is to use the linear damage rule which is both simple and requires a minimum of input information. The experiments to be described will be used to examine the validity of the linear damage rule. In addition to testing the linear damage rule, we will examine the feasibility of using a non-destruction damage detection method based on measuring the stress in the thermally grown oxide (TGO) using photoluminescence piezospectroscopy (PLPS). This method has shown some success in remaining life prediction for lab samples tested at constant conditions [2]. The challenge for non-constant conditions is significantly greater even for lab samples as discussed here. The use of PLPS measurements to predict the lives of aircraft engine parts will be even more difficult, but this work seeks to see to what degree this method can be made to work for the more difficult case of non-constant cyclic conditions. Feasibility of such predictions, as will be 
shown, depends in part of what sort of information is available about the thermal history of the part. We include one case for which the information required is not currently collected in the event that rapidly growing condition monitoring technology may someday include the required information.

In this work, tests are carried out in which the temperature history is changed during the test. The peak temperature or the cycle duration was changed at roughly half of the expected life of the samples. This is a simplified load history designed to see if a simple linear damage rule applies. Baseline samples in this study were previously tested under constant conditions [2]. These constant condition test results were then used as input to test the accuracy of the linear damage rule. In addition, extensive measurements of TGO stress taken by photoluminescence piezospectroscopy (PLPS) of the constant history samples reported for these samples in [2] was shown to have potential for nondestructive prediction of remaining life. The technique, invented by Paton et al. [5] has been useful in non-destructively measuring the stress in the TGO and is based on the frequency shift in the $\mathrm{Cr}^{3+}$ ions within the TGO. The impact of non-constant temperature and cycle duration on PLPS data and life prediction was also examined [6].

Before presenting the results a few preliminary comments are in order. First we note that the linear damage rule takes no account of the physical damage mechanisms involved however it is widely used because it requires a very minimum amount of information. In contrast, mechanism based methods require extensive information. For example, in one recent study, life prediction required finite element modeling using an advanced constitutive model as well as measurements of rumpling and oxidation kinetics collected from over 1000 micrographs [7]. Mechanism based approaches such as in [7] are beyond the scope and intent of this experimental program and often infeasible in an industrial context. Second, with respect to using measured TGO stress to predict remaining life there are several challenges. Generally when measuring 
TGO stress on turbine blades there is some variation in stress with locations on a given component however as shown in $[8,9]$ this variation is typically manageable. In the study conducted by Sohn et al [9], stresses at the pressure, suction, and leading edge side all dropped off significantly with thermal cycling. Initial stresses of $3.14+/-0.25 \mathrm{GPa}$ at the pressure side, $3.15+/-0.12 \mathrm{GPa}$ at the suction side, and $3.58+/-0.23 \mathrm{GPa}$ at the leading edge dropped to 1.64 +/- $0.18 \mathrm{GPa}, 1.41+/-0.21 \mathrm{GPa}$, and $1.47+/-0.32 \mathrm{GPa}$ in those locations respectively indicating that the surface curvature and local bond coat roughness or other factors did not excessively change the stress decay during thermal cycling. Typically on an individual blade, the variation in measured stress is less than $15 \%[8]$ and to be conservative the location with the greatest stress drop would be used to characterize the blade.

In addition there tends to be considerable consistency as to where on a blade the spallation occurs in a given engine and blade row. We have had the opportunity to study 100 turbine blades from five different engines each with a different number of operational hours. The majority of blades examined had spallation in only three different locations with the most frequent being in the center of the pressure side. Accordingly, in practice it is expected that measurements would be taken from a limited number of known critical locations for which there is some but not extreme variation in measured stress.

In carrying out this study there were many possible choices as to the nature of nonconstant condition tests to carry out. Since non-constant conditions tests are new we choose the conditions based on what generally is the most challenging for the linear damage rule in metal fatigue, namely a change from test condition A to condition B at an estimated life fraction of 0.5. Actual service is likely to involve mixed conditions for which sequence effects if any would tend to average out compared to the tests involving only two conditions applied in sequence making the tests run likely to be strong tests for the linear damage rule. 


\section{Experimental Setup}

\subsection{TBC Specimens}

In this study, two types of TBC's samples were utilized (Figure 1). Both types consisted of $25.4 \mathrm{~mm}$ diameter disk-shaped coupons that were $3.2 \mathrm{~mm}$ in thickness with YSZ topcoats deposited by electron beam physical vapor deposition (EB-PVD). Type I TBC samples consisted of 150 micron 7\% weight $\mathrm{Y}_{2} \mathrm{O}_{3}$ (YSZ) stabilized zirconia electron physical vapor deposited (EBPVD) top coat, and a 75 micron grit blasted platinum nickel-aluminide bond coat [(Ni, $\mathrm{Pt}) \mathrm{Al}]$. The outwardly grown chemical vapor deposition single phase platinum aluminide coating was formed at $1080^{\circ} \mathrm{C}$ and grit blasted prior to electron beam physical vapor deposition (EB-PVD) of the ceramic top coat.

Type II TBC consisted of 175 micron 7\% weight $\mathrm{Y}_{2} \mathrm{O}_{3}$ (YSZ) stabilized zirconia EB-PVD top coat, and a 55-60 micron grit blasted platinum modified nickel-aluminide bond coat. The bond coat on Type II was inwardly grown at $982^{\circ} \mathrm{C}$ using pack cementation. In addition, both types of TBC's also had contained an initial thermally grown oxide (TGO). This layer, typically 0.5 microns prior to cycling, consisted of an alpha aluminum oxide that forms during heat treatment. The compositions of these bond coats are shown in Table I.

\subsection{Furnace Cycling Tests}

Furnace cycling tests were conducted in bottom-loading thermal cycling furnaces made by CM Furnaces Inc. The type $\mathrm{S}$ thermocouple that controlled the furnace temperature was welded to the back of a superalloy dummy sample in the center of the furnace. Three additional thermocouples were mounted in three of the four corners of the furnace and agreed at steady state with the control thermocouple within $5^{\circ} \mathrm{C}$. 
The 1-hour cycles consisted of a 10-minute heat-up to the cycle temperature, followed by a dwell for 40 minutes at the maximum temperature. The final step was a 10-minute forced-air cool. The 24-hour cycle test consisted of the same 10-minute heat up to temperature, followed by a 1430-minute hold and then a 10-minute forced air quench. The samples subjected to the twostage cyclic tests were first cycled at a test condition which will be referred to as condition A until approximately fifty percent life, and then tested at a second test condition to be called B until failure. The order in which the conditions are applied is likely to matter and this is consistently designated as condition A first followed by condition B.

Initial baseline testing, reported in [2] involved cycling separate sets of samples at $1121^{\circ} \mathrm{C}$ and $1151^{\circ} \mathrm{C}$ using 1 -hour and 24 -hour hold times to determine the average failure life of specimens. For Type I TBC's, eleven specimens were cycled at $1121^{\circ} \mathrm{C}$ and nine at $1151^{\circ} \mathrm{C}$ all using 1-hour cycles. In addition, eight were cycled at $1121{ }^{\circ} \mathrm{C}$ using 24 -hour hold time. For Type II TBC's, six were cycled at $1121^{\circ} \mathrm{C}$ and four at $1151^{\circ} \mathrm{C}$ using 1 -hour cycles while two were cycled at $1121^{\circ} \mathrm{C}$ using 24 -hour hold times. The average lives of these samples [2] were used to identify approximately 50\% life fraction when running two stage tests switching from test condition A to B.

\subsubsection{Multiple Amplitude Testing}

For the multiple temperature tests, two types of testing procedures were utilized, tests in which samples were subjected to $1121^{\circ} \mathrm{C}$ until about half the expected life followed by $1151{ }^{\circ} \mathrm{C}$ and in the reverse order. For the multiple hold time tests, two tests were used all at $1121^{\circ} \mathrm{C}$ in which cycling was done using 1-hour hold times for the first half and then changed to 24 hours until failure, and in the reverse order. 


\subsection{Photoluminescence Piezospectroscopy (PLPS)}

Photoluminescence Piezospectroscopy was utilized in this study throughout the duration of furnace cycling to determine the stress state within the TGO. Photoluminescence spectroscopy measurements of TGO stress were carried out using a Renishaw ${ }^{\mathrm{TM}} \operatorname{Raman}^{\mathrm{TM}} 2000$ microscope utilizing a $514 \mathrm{~nm}$ laser to stimulate fluorescence. The resulting peak location of the fluorescence spectra are related to the TGO stress [10], [11], [12], and [13]. To obtain this peak shift the R1 and R2 spectra are fit to a Gaussian-Lorentzian Function using software that automatically does a parabolic background subtraction. It has been documented in the literature [14], [15], [16], [17], [18], that the location of both the R1 and R2 shift in a systematic way with stress level such that the spacing is a known function of position. Initial peak fitting was done using the Grams $32^{\mathrm{TM}}$ Spectral Notebase software in which the R1 and R2 are independently fit based on a manually input initial guess. Equivalent results can be more conveniently obtained incorporating the known stress dependent relation of the $\mathrm{R} 1$ and $\mathrm{R} 2$ peak position in a manner similar to that described in details in $[13,19]$. All collected spectra had a minimum of 50,000 counts to achieve an adequate signal to noise ratio. At specific intervals during furnace cycling PLPS measurements were made on the TBC. The spectra were collected from 40 random locations on the disk. The average stress values and standard deviations were extracted and studied as a function of cycles and life fraction.

As thermal cycling is carried out on TBC's, stresses in the thermally grown oxide tend to increase in the first 5-10\% of TBC life due to the in-plane growth of non-planar TGO [6]. Following this increase, stress decays due to various damage events and residual stresses in the TGO significantly decrease as parts are subjected to high temperatures [9]. 


\section{Experimental Results}

\subsection{Type I TBC Spallation Lives in Constant Cycles}

For the baseline testing to determine the expected life at a certain temperature or hold time, data previously generated and presented in [2] was used. The average spallation life was 677 cycles for the eleven samples held at $1121^{\circ} \mathrm{C}$ using 1-hour hold times and 358 cycles for the nine samples held at $1151^{\circ} \mathrm{C}$ using 1-hour hold times. For the eight samples run at 24-hour hold times at $1121^{\circ} \mathrm{C}$, the average life was found to be 45 cycles (1080 hours).

\subsection{Type I TBC Spallation Lives in Multiple History Tests}

Six Type I samples underwent multiple amplitude furnace cycling in which the temperature and cycle duration were changed part-way through the cycling. Table II highlights the four samples subjected to multiple temperatures and the associated cycles for each test. Table III shows the cycle history for the two samples subjected to a change in cycle duration both done at $1121{ }^{\circ} \mathrm{C}$ and the respective cycles at each specific condition. Using constant cycle data at each temperature and hold time, tests were switched from condition A to B at approximately $50 \%$ life fraction of condition A.

\subsection{Type I TBC TGO Stress as a Function of Life Fraction for Multiple History Tests}

PLPS measurements were conducted on the thermally cycled TBC specimens at periodic intervals. The average TGO stress versus life fraction for the four samples that were subjected to multiple-temperature tests is shown in Figure 2 along with the $1121^{\circ} \mathrm{C}$ and $1151^{\circ} \mathrm{C} 1$-hour hold 
time baseline tests. For the multi-temperature tests in which the samples were cycled each to half their cyclic life at $1121^{\circ} \mathrm{C}$ using 1 -hour cycles and then cycled to failure at $1151^{\circ} \mathrm{C}$, the slope of the TGO stress curve increased slightly during the transition to the new temperature, and then decreased to approximately the original slope over time. For the tests carried out at $1151^{\circ} \mathrm{C}$ followed by $1121^{\circ} \mathrm{C}$, the stress versus life fraction curve remained constant during the transition to the new temperature and remained mostly unchanged.

Figure 3 is a plot of the TGO stress versus life fraction for the two samples that were subjected to the multiple hold time tests with a single maximum temperature of $1121^{\circ} \mathrm{C}$ alongside the baseline 1 -hour and 24 -hour $1121^{\circ} \mathrm{C}$ tests. It is clear from the figure that these tests are not single valued independent of the hold time. This is not surprising because for tests run to failure at a single hold time the curves are not independent of hold time. The possible interpretations of the behavior in Figure 3 will be presented in the discussion section.

\subsection{Type II TBC Spallation Lives in Constant Cycles}

Similar to Type I TBC's, baseline testing was conducted previously [2] on various Type II TBC samples to determine the average life at various temperatures and hold times. The average life of the six samples cycled using 1 -hour $1121^{\circ} \mathrm{C}$ tests, was 563 cycles, while for the four samples using $1151^{\circ} \mathrm{C}$ tests, average life was 363 cycles.

\subsection{Type II TBC Spallation Lives in Multiple History Tests}

Both Type II TBC's underwent changes in cycle temperature. The test conditions and cycles for each test are summarized in Table IV. Samples were cycled to approximately 50\% life fraction at condition $\mathrm{A}$, and then to failure at condition B using average spallation data obtained from constant cycling. 


\subsection{Type II TBC TGO Stress as a Function of Life Fraction for Multiple History Tests}

The result for Type II TBC TGO stress versus life fraction is plotted in Figure 4 alongside baseline $1121^{\circ} \mathrm{C}$ and $1151^{\circ} \mathrm{C} 1$-hour tests. For the tests carried out at $1121^{\circ} \mathrm{C}$ followed by $1151^{\circ} \mathrm{C}$, there was an increase in the measured stress of the sample during the transition to the higher test temperature, but the stress eventually decreased and remained relatively unchanged to failure. A different trend was noted for the tests carried out at $1151^{\circ} \mathrm{C}$ followed by $1121^{\circ} \mathrm{C}$. TGO stress was left mostly unchanged during the transition to $1121^{\circ} \mathrm{C}$ and was not as substantial as that for tests carried out at $1121^{\circ} \mathrm{C}$ followed by $1151^{\circ} \mathrm{C}$.

\subsection{Standard Deviation of Stress Measurements}

In the data collected the standard deviation shows a modest increasing trend in life fraction as shown in [7] where for Type I samples deviation starts at small life fractions as 0.06 GPa to about 0.15 GPA near failure and for Type II samples deviation starts at about $0.1 \mathrm{GPa}$ at small life fraction to about 0.3 GPA near failure. 


\section{Discussion}

In the following results, the error in life prediction for all cases is based on total life error. The measurements were made with regards to the total remaining life in each of the multiple amplitude tests and are represented in this way. For life prediction scenarios, the error on the remaining life will also be given in parentheses. When dealing with the life prediction error on the remaining life, the error is roughly twice as high as the total life error because the remaining life is approximately half the total life because of the way the tests were run. We note that a nearly constant TGO stress value just prior to failure is observed in all the tests reported here. It is a matter of speculation why this is so but the data collected in this paper and elsewhere $[2,4]$ shows the same behavior. Similar behavior has not been seen in samples with other types of bond coats [20]. All the systems that show this dramatic drop in TGO stress also rumple. Rumpling would lengthen the TGO and logically lead to compressive stress reduction as observed.

Rumpling has been shown to correlate with TGO thickness $[6,21]$ as well. Stress reduction may be a marker for rumpling progress and TGO growth, both of which are related to damage. However this is just a hypothesis to explain the stress drop and constant value at failure at this point. We are however exploiting the observation that the failure in the present case occurs at quite consistent value of TGO stress [2].

\subsection{Linear Damage Rule for TBC Life Fractions}

For the first time, multi-stage furnace cycling tests were conducted to try and validate the linear damage rule to better predict the remaining life of the TBC samples. The linear damage rule in this case is given as Equation 1 where it is desired that the damage, $\mathrm{D}$, be equal to one for 
the linear damage rule to be exactly satisfied. Damage was calculated for each specimen that underwent two-stage furnace cycle testing. For the tests, when $\mathrm{D}>1$ the linear damage rule would under predict the remaining life and hence is conservative. Correspondingly, for $\mathrm{D}<1$ the linear damage rule over predicted the remaining life and is non conservative. In the following analysis, we use all the average life values in the linear damage rule. The actual damage, $\mathrm{D}$ at failure is given in Table V and VI for Type I and II TBC's where the damage fractions at each specific stage are calculated from the fractions in Equation 1.

$$
D=\frac{\text { Cycles at Condion } A}{\text { Average Cycles to Failure at } A}+\frac{\text { Cycles at Condition } B}{\text { Average Cycles to Failure at } B}
$$

Equation 1: Linear Damage Rule Equation for Multi-amplitude Tests

First, for the Type I specimens undergoing multi-temperature tests, the linear damage rule is reasonably satisfied. The damage D determined for samples subjected to this loading condition ranged from 1.018 to 1.122 for total TBC damage yielding a conservative life prediction. For the Type I samples subjected to multiple hold times, when sample LE 04 underwent 24-hour cycles followed by 1 -hour cycles at $1121^{\circ} \mathrm{C}$, the total TBC damage fraction was found to be 0.928 . However, for sample LE 33 that underwent 1-hour cycles followed by 24-hour cycles, TBC damage parameter $\mathrm{D}$ was found to be 0.753 suggesting that 1-hour cycles are more damaging than the linear damage rule would suggest.

For the Type II specimens that underwent multi-temperature tests, the linear damage rule is once again reasonably satisfied. Both samples subjected to this loading condition had TBC damage in the range of 0.89 to 0.84 ; multiple hold time tests were not conducted on Type II TBC's. 


\subsection{Remaining Life Estimates from TGO Stress versus Life Fraction Curves}

In addition to utilizing the linear damage rule on multi-amplitude testing, the remaining life of TBC samples can also be estimated from PLPS. In the simple case of single amplitude conditions, reading stress values at the specific test condition will provide a reasonable estimate of remaining life. In discussing non-constant condition testing, we need to pay attention to which cyclic condition is applied first. We will label the first applied condition as A and the second condition applied as B. For the non-constant tests the success of the life prediction depends on how much information is available. Three different cases were examined.

\section{Case 1: Averaging Multiple History Curves}

In this case we assume that all that is known is a single measured stress value and the number of cycles or flight hours at which the measurement is made. To use this limited information for life prediction, the TGO stress versus life fraction curves for all baseline tests were averaged to produce a single stress vs. life fraction curve. That curve was used to predict the life for the multiple amplitude tests. In this case, it is assumed that all that is known is the measured stress value at half the expected life and the number of cycles to that point. By averaging baseline 1 -hour tests at $1121^{\circ} \mathrm{C}$ and $1151^{\circ} \mathrm{C}$ along with the 1 -hour $1121^{\circ} \mathrm{C}$ and 24 -hour $1121^{\circ} \mathrm{C}$ tests a new curve was generated and compared to the TGO stress versus life fraction curves for the multiple amplitude tests. By taking the TGO stress measurements for all baseline test conditions and averaging them together an average composite curve was created and compared to the variable TGO stress versus life fraction curves. Various stress values and corresponding life fractions were compared for the new averaged baseline to the two-stage tests 
for Type I TBC's. This approach was not successful with the total life error ranging from $3 \%$ to 91\%. Insufficient data was available to attempt this approach on Type II samples.

\section{Case 2: Extrapolating Multiple History Curves}

Based on observations of the data collected, the stress at failure is relatively constant at approximately $1.2 \mathrm{GPa}$ [2] after the condition changes. Accordingly, this presents an opportunity to make predictions if two stress measurements are made and the stress is extrapolated to the critical value for failure. In actual cases the measurements would be made at intervals that were convenient. There are clearly many ways to do this and here we somewhat arbitrarily choose to take measurements at life fractions of 0.5 and 0.75 to give a sense of how well or badly this type of procedure might work. Baseline data is not needed in this approach. The results from this procedure are shown in Table VII for Type I TBC's. In each case, the number quoted is the predicted life at failure divided by the actual life at failure where 1.0 would indicate perfect agreement and numbers larger than 1.0 indicate that the actual life is shorter than the predicted one and hence are anticonservative. The predicted life divided by the actual life was between 0.87 and 1.045 for a step change in temperature and between 1.34 and 2.38 for a step change in hold time. Not enough testing and information was available to attempt this approach on Type II samples. As with the linear damage rule, the predictions for a step change in temperature were good and for a change in cycle durations the predictions were not as good. The stress versus life fraction curves for the two 24-hour tests are not straight with the slope increasing rapidly near the end of the test and as a result linear extrapolation was not very successful.

\section{Case 3: Stress, Life Fraction and the Transition from Condition A to B is Known}

The final assumed circumstance for estimating remaining life involves the scenario where the TGO stress, hot time, and cycles after the transition from condition A to B are known. 
Clearly this is not a likely scenario for an aircraft engine. The goal is to use the single stress measured at the transition and knowledge of the baseline TGO stress versus life fraction curve to determine the remaining life. The main challenge is the fact that there is an offset between the stress level at the transition and the constant condition curve for condition B as seen in Figure 5. This offset is the difference in stress at the baseline condition B compared to the multiple amplitude tests at B for the stress values taken just after the transition to condition $\mathrm{B}$. In the cycling conducted, the transition point was chosen to be at a life fraction of approximately 0.5 . Table VIII shows the size of these offsets for the various tests. The procedure is to extend a stress versus life fraction line using the curve from the base line tests at condition $\mathrm{B}$. This is done simply by translating the reference curve from the constant amplitude tests for condition B such that the stress value exactly matches the value measured in the sample at the time of the condition change. The failure life is predicted using the location where the now adjusted baseline test curve intersects the known critical value at failure. This is similar to case 2 , but in this case the extrapolation is based on the exact curve from the base line test data at condition B and not a straight-line extrapolation. No second measurement is required. The last column in Table VIII shows the predicted failure life divided by the actual life. In addition, the error on total life prediction is represented as well as the error on the remaining life. The results are reasonable with the largest error in the ratio of the predicted to actual life of 1.26.

\subsection{Failure Modes}

It is worth noting that the failure locations in 1-hour tests moved from a failure at the local grain boundary ridges leaving most of the TGO behind to failures occurring involving separation of the entire TGO to bond coat interface in the 24-hour tests as shown in Figure 6. The ridge top failure mode has been well descried and modeled using fracture mechanics in [22]. For failures occurring in two different modes, as occurs in tests involving hold time changes the linear 
damage rule would not be expected to work well, consistent with the results obtained in this study.

\section{Conclusion}

Overall, utilizing two stage non-constant furnace cycling tests for the first time on TBC specimens, the linear damage rule was shown to do a reasonable job at remaining life prediction for samples undergoing a change in temperature during cycling with a maximum error of $16 \%$ and less well for tests samples undergoing multiple hold times with a maximum error of $24 \%$. These conclusions held for the two types of samples tested here. The use of measured TGO stress to predict remaining life followed the same pattern, working better when cycle temperature was suddenly changed part way through the test but not nearly as well if the cycle hold time was suddenly changed.

One of the aspects of this work was to investigate how remaining life can be estimated by non-destructively measuring the TGO stress using photoluminescence piezospectroscopy (PLPS). It was shown that in the case of a step change in conditions, it is not possible to estimate remaining to a useful accuracy from a single stress measurement and no other information. The measured stress at failure is consistently around $1 \mathrm{GPa}$ in the samples examined in this study similar to the value obtained in constant condition tests [2]. If two measurements of stress are made the rate of change of stress with time or cycles can be estimated and the time to reach the critical stress can be predicted within the limits specified. For Type I samples involving sudden temperature change the life can be estimated to a life fraction that at worst is off by $13 \%$ while for a sudden change in cycle duration the estimate is at worst $138 \%$. The worst estimate is for the case cycling for 24 -hours at $1121^{\circ} \mathrm{C}$ then changing the hold time to 1-hour to failure. 
If the temperature and cycle duration are known for the remainder of the test, a single measurement of stress can be combined with the life fraction vs. TGO stress curve known from base line testing and the conditions can be used to predict failure by seeing when the stress is expected reach the critical value associated with failure. The result in maximum errors for temperature change was $16 \%$ for Type I TBC's, $26 \%$ for Type II TBC's and for changes in cycle duration the error was $5 \%$. We note that such detailed knowledge in the case of aircraft is not likely to be available even for a specific critical location. Since stress measurement may require opening the engine case, reducing the measurement need to a single measurement is important. It is not entirely unexpected that change in hold time tests are more difficult to predict since the failure mode changes from one involving separation of the TGO at asperities at short hold times to one that is dominated by nearly total TGO to bond coat separation in the 24-hour tests. The tests run are probably a worst case since only two conditions were used and any sequence effects would not average out. An important question yet to be answered is what sort of accuracy can be expected from a linear damage rule or from PLPS measurements for multilevel tests or random temperature and hold time tests. In analogue with traditional fatigue testing, improved accuracy may be possible if sequence effects average out. Such experiments are encouraged.

\section{Acknowledgements}

This research was funded by the Department of Energy (DOE) under the Advanced Gas Turbine System Research (AGTSR) Program (Contract \#99-01-SR073) and the Three Parameters Program (Contract \#02-01-SR97), administered by the South Carolina Institute for Energy Studies, Clemson University with Dr.Richard Wenglarz as the program monitor. The authors wish to thank Dr. K.S. Murphy, Howmet Corporation, for specimens used in this study. 


\section{References}

[1] Beele W., Marijnissen G., Vvan Lieshout H., Surface \& Coatings Technology 120-121 61 (1999).

[2] Swetha Sridharan, Liengde Xie and Eric H. Jordan and Maurice Gell, "Stress Variation with Thermal Cycling in the Thermally Grown Oxide of an EB-PVD Thermal Barrier Coating, Surface Coatings and Technology, Vol 179, issues 2-3, Feb,2004, pp. 286-298.

[3] Swetha Sridharan, Liengde Xie and Eric H. Jordan and Maurice Gell, " Damage Evolution in an Electron Beam Physical Vapor Deposited Thermal Barrie Coating as a Function of Cycle Temperature and time," Materials Science and Engineering A 393 (2005), 51-62.

[4] Mei Wen, Eric H. Jordan and M. Gell. Evolution of Photo-stimulated Luminescence of EBPVD Thermal Barrier Coatings, Materials Science and Engineering A, 398 (2005), 99-107.

[5] N.E. Paton, K.S. Murphy, D.R. Clarke, US Patent \#6,072,568, 2000.

$[6$

] Sridharan, Swetha, "Thermal cycle parameter effects on the stress state, failure mechanisms and life prediction of thermal barrier coatings" (2005). Doctoral Dissertations. Paper AAI3193744. http://digitalcommons.uconn.edu/dissertations/AAI3193744

[7] Ahmadian, S., Thistle, C., Jordan, E. H. (2013), Experimental and Finite Element Study of an Air Plasma Sprayed Thermal Barrier Coating under Fixed Cycle Duration at Various Temperatures. Journal of the American Ceramic Society, 96: 3210-3217. doi: $10.1111 /$ jace. 12552

[8] Kelley, Colin D., "Nondestructive Evaluation of Engine Run Turbine Blades Using Laser Ablation and Photoluminesence Stress Measurements" (2011). Master's Theses. Paper 161. http://digitalcommons.uconn.edu/gs theses/161

[9] Sohn, Y. H., Schlichting, K. Vaidyanathan, Jordan E. H. and Gell, M.,"Non-Destructive Evaluation of Residual Stress for Thermal Barrier Coated Turbine Blades by $\mathrm{Cr}^{3+}$ 
Photoluminescence Piezo- Spectroscopy," Communications Met. Trans. A., Vol. 31a, p. 23882391,Sept 2000.

[10] Lipkin D. M., Clarke D. R., Journal of Applied Physics 77 [5] 1855-1863 (1995).

[11] Christensen R. J., Lipkin D. M., Clarke D. R., Murphy K. S., Applied Physics Letters 69 [24] 3754-3756 (1996).

[12] Lipkin D. M., Clarke D. R., Oxidation of Metals 45267 (1996).

[13] Clarke D. R., Christensen R. J., Tolpygo V. K., Surface \& Coatings Technology 94-95 8993 (1997).

[14] J. A. Nychka et al., Surface and Coatings Technology 163-164, 87 (2003).

[15] A. Selcuk, A. Atkinson, Materials Science and Engineering A 335, 147 (2002).

[16] Q. Ma, D.R. Clarke J. Am. Ceram. Soc., 76 (1993), p. 1433

[17] Q. Ma, D.R. Clarke J. Am. Ceram. Soc., 77 (1994), p. 298

[18] J. He, D.R. Clarke J. Am. Ceram. Soc., 78 (1995), p. 1347

[19] J. A. Nychka, D. R. Clarke, Surf. Coat Technol. 146-147 (2001)

[20] Schlichting, K.W., Vaidyanathan, K., Sohn, Y.H., Jordan, E.H., Gell, M., Padture, N.P. Application of $\mathrm{Cr} 3+$ photoluminescence piezo-spectroscopy to plasma-sprayed thermal barrier coatings for residual stress measurement (2000) Materials Science and Engineering A, 291 (1-2), pp. 68-77.

[21] Mei Wen, Eric H. Jordan, Maurice Gell, Analysis of localized damage in EB-PVD/(Ni, Pt)Al thermal barrier coatings, Surface and Coatings Technology, Volume 200, Issues 18-19, 8 May 2006, pp. 5193-5202

[22] Vaidyanathan, K., Jordan, E.H., Gell, M. Surface geometry and strain energy effects in the failure of a (Ni, Pt)Al/EB-PVD thermal barrier coating (2004) Acta Materialia, 52 (5), pp. 11071115. 
Tables

Table I: Composition and Thickness of the two TBC's studied [6]

\begin{tabular}{|c|c|c|c|c|c|}
\hline \multirow[t]{2}{*}{ Type } & \multirow[t]{2}{*}{$\begin{array}{l}\text { Superalloy } \\
\text { Substrate }\end{array}$} & \multicolumn{2}{|c|}{ Bond Coat } & \multicolumn{2}{|c|}{$\begin{array}{l}\text { Ceramic } \\
\text { (7 YSZ) }\end{array}$} \\
\hline & & Type & $\begin{array}{c}\text { Thickness } \\
\qquad(\mu \mathrm{m})\end{array}$ & Type & $\begin{array}{c}\text { Thickness } \\
\qquad(\mu \mathrm{m})\end{array}$ \\
\hline $\mathbf{I}$ & $\begin{array}{c}\text { Single } \\
\text { Crystal } \\
\text { CMSX-4 }\end{array}$ & $\begin{array}{c}\text { Grit Blasted on } \\
\text { Outward Diffusing } \\
\text { Single Phase } \\
\text { Platinum Modified } \\
\text { Nickel Aluminide }\end{array}$ & 75 & $\begin{array}{l}\text { EB- } \\
\text { PVD }\end{array}$ & 150 \\
\hline II & $\begin{array}{c}\text { Single } \\
\text { Crystal } \\
\text { CMSX-4 }\end{array}$ & $\begin{array}{c}\text { Grit Blasted on } \\
\text { Inward Diffusing } \\
\text { Type Single Phase } \\
\text { Platinum Modified } \\
\text { Nickel Aluminide }\end{array}$ & $55-60$ & $\begin{array}{l}\text { EB- } \\
\text { PVD }\end{array}$ & 175 \\
\hline
\end{tabular}


Table II: Spallation Lives of Type I TBC's Subjected to Multiple Temperature Tests [6]

\begin{tabular}{|c|c|c|}
\hline Sample Designation & $\begin{array}{c}\text { First Exposure } \\
\text { Temperature, } \mathbf{T}_{\mathbf{1}}\left({ }^{\circ} \mathbf{C}\right)\end{array}$ & $\begin{array}{c}\text { Second Exposure } \\
\text { Temperature, } \mathbf{T}_{\mathbf{2}}\left({ }^{\circ} \mathbf{C}\right)\end{array}$ \\
\hline $\begin{array}{c}\text { \# Cycles at each } \\
\text { Temperature }\end{array}$ & $1121^{\circ} \mathrm{C}$ & $1151^{\circ} \mathrm{C}$ \\
\hline LD 74 & 335 & 205 (Failed) \\
\hline $\begin{array}{c}\text { \# Cycles at each } \\
\text { Temperature }\end{array}$ & $1121^{\circ} \mathrm{C}$ & $225($ Failed $)$ \\
\hline LD 82 & $1151^{\circ} \mathrm{C}$ \\
\hline \# Cycles at each \\
Temperature
\end{tabular}


Table III: Spallation Lives of Type I TBC's Subjected to Multiple Hold Time Tests [6]

\begin{tabular}{|c|c|c|}
\hline Sample & $\begin{array}{c}\text { First Hold Time, } \mathbf{t}_{\mathbf{1}} \\
\text { (minutes) }\end{array}$ & $\begin{array}{c}\text { Second Hold Time, } \mathbf{t}_{\mathbf{2}} \\
\text { (minutes) }\end{array}$ \\
\hline LE 33 & 45 & 1425 \\
\hline $\begin{array}{c}\text { \# Cycles at each Hold } \\
\text { Time }\end{array}$ & 345 & 11 (Failed) \\
\hline LE 04 & 1425 & 45 \\
\hline $\begin{array}{c}\text { \# Cycles at each Hold } \\
\text { Time }\end{array}$ & 22 & 298 (Failed) \\
\hline
\end{tabular}


Table IV: Spallation Lives of Type II TBC's Subjected to Multiple Temperature Tests [6]

\begin{tabular}{|c|c|c|}
\hline Sample & $\begin{array}{c}\text { First Exposure } \\
\text { Temperature, } \mathbf{T}_{\mathbf{1}}\left({ }^{\circ} \mathbf{C}\right)\end{array}$ & $\begin{array}{c}\text { Second Exposure } \\
\text { Temperature, } \mathbf{T}_{\mathbf{2}}\left({ }^{\circ} \mathbf{C}\right)\end{array}$ \\
\hline LV 37 & $1121^{\circ} \mathrm{C}$ & $1151^{\circ} \mathrm{C}$ \\
\hline $\begin{array}{c}\text { \# Cycles at each } \\
\text { Temperature }\end{array}$ & 261 & 157 (Failed) \\
\hline LV 48 & $1151^{\circ} \mathrm{C}$ & $1121^{\circ} \mathrm{C}$ \\
\hline $\begin{array}{c}\text { \# Cycles at each } \\
\text { Temperature }\end{array}$ & 165 & 218 (Failed) \\
\hline
\end{tabular}


Table V: Linear Damage Coefficients for Type I TBC's [6]

\begin{tabular}{|c|c|c|c|c|c|c|}
\hline Sample & $\frac{\text { Test Condition }}{\underline{\mathrm{A}}}$ & $\begin{array}{c}\text { Damage } \\
\text { Fraction } \\
\text { at } \mathrm{A}\end{array}$ & $\begin{array}{c}\underline{\text { Test }} \\
\text { Condition } \\
\underline{B}\end{array}$ & $\begin{array}{c}\text { Damage } \\
\text { Fraction at B }\end{array}$ & $\begin{array}{l}\underline{\text { Total }} \\
\underline{\text { TBC }} \\
\text { Damage }\end{array}$ & $\begin{array}{c}\text { Percent } \\
\text { Error (\%) }\end{array}$ \\
\hline LD 73 & $1121^{\circ} \mathrm{C}$ 1-hour & 0.494 & $\begin{array}{l}1151^{\circ} \mathrm{C} 1- \\
\text { hour }\end{array}$ & 0.573 & 1.067 & 6.7 \\
\hline LD 74 & $1121^{\circ} \mathrm{C}$ 1-hour & 0.494 & $\begin{array}{l}1151^{\circ} \mathrm{C} 1- \\
\text { hour }\end{array}$ & 0.628 & 1.122 & 12.2 \\
\hline LD 82 & $1151^{\circ} \mathrm{C} 1$-hour & 0.5167 & $\begin{array}{l}1121^{\circ} \mathrm{C} 1- \\
\text { hour }\end{array}$ & 0.5022 & 1.018 & 1.8 \\
\hline LD 84 & $1151^{\circ} \mathrm{C} 1$-hour & 0.5167 & $\begin{array}{l}1121^{\circ} \mathrm{C} 1- \\
\text { hour }\end{array}$ & 0.604 & 1.121 & 12.1 \\
\hline LE 33 & $1121^{\circ} \mathrm{C} 1$-hour & 0.509 & $\begin{array}{l}1121^{\circ} \mathrm{C} 24- \\
\text { hour }\end{array}$ & 0.244 & 0.753 & 24.7 \\
\hline LE 04 & $\begin{array}{l}1121^{\circ} \mathrm{C} 24- \\
\text { hour }\end{array}$ & 0.488 & $\begin{array}{l}1121^{\circ} \mathrm{C} 1- \\
\text { hour }\end{array}$ & 0.4401 & 0.928 & 7.2 \\
\hline
\end{tabular}




\begin{tabular}{|c|c|c|c|c|c|c|}
\hline Sample & \begin{tabular}{c}
\multicolumn{1}{c}{ Test } \\
Condition A
\end{tabular} & $\begin{array}{c}\text { Damage } \\
\text { Fraction at A }\end{array}$ & \begin{tabular}{c}
\multicolumn{1}{c}{ Test } \\
Condition B
\end{tabular} & $\begin{array}{c}\text { Damage } \\
\text { Fraction at B }\end{array}$ & $\begin{array}{c}\text { Total TBC } \\
\text { Damage }\end{array}$ & $\begin{array}{l}\text { Percent } \\
\text { Error (\%) }\end{array}$ \\
\hline LV 37 & $\begin{array}{l}1121^{\circ} \mathrm{C} 1- \\
\text { hour }\end{array}$ & 0.4635 & $\begin{array}{l}1151^{\circ} \mathrm{C} 1- \\
\text { hour }\end{array}$ & 0.4325 & 0.89 & 11 \\
\hline LV 48 & $\begin{array}{l}1151^{\circ} \mathrm{C} 1- \\
\text { hour }\end{array}$ & 0.4545 & $\begin{array}{l}1121^{\circ} \mathrm{C} 1- \\
\text { hour }\end{array}$ & 0.387 & 0.841 & 15.9 \\
\hline
\end{tabular}

Table VI: Linear Damage Coefficients for Type II TBC's [6] 
Table VII: Total life fractions for multiple amplitude tests for Type I TBC's and error on total and predicted life

\begin{tabular}{|l|l|l|}
\hline \multicolumn{1}{|c|}{ Type I TBC } & \multicolumn{1}{|c|}{$\begin{array}{c}\text { Predicted Life } \\
\text { Actual Failure Life }\end{array}$} & \multicolumn{1}{c|}{$\begin{array}{c}\text { Total Life Error } \\
\text { (Remaining Life Error) }\end{array}$} \\
\hline $1121^{\circ} \mathrm{C}$ to $1151^{\circ} \mathrm{C}(1-$ hour) & 1.045 & $4.5 \%$ \\
& & $(14.52 \%)$ \\
\hline $1151^{\circ} \mathrm{C}$ to $1121^{\circ} \mathrm{C}(1-$ hour $)$ & 0.87 & $13 \%$ \\
\hline $1-$ hour to 24 -hour $\left(1121^{\circ} \mathrm{C}\right)$ & 1.34 & $(24 \%)$ \\
\hline 24-hour to 1 -hour $\left(1121^{\circ} \mathrm{C}\right)$ & 2.38 & $34 \%$ \\
& & $(103 \%)$ \\
\hline
\end{tabular}


Table VIII: Stress offset, total life, and error for multiple amplitude tests

\begin{tabular}{|c|c|c|c|}
\hline Type I TBC & $\begin{array}{c}\text { Offset between } \\
\text { baseline and } \\
\text { condition B (GPa) }\end{array}$ & $\frac{\text { Predicted Life }}{\text { Actual Failure Life }}$ & $\begin{array}{c}\text { Total Life Error } \\
\text { (Remaining Life } \\
\text { Error) }\end{array}$ \\
\hline $\begin{array}{l}1121^{\circ} \mathrm{C} \text { to } 1151^{\circ} \mathrm{C} \\
\text { (1-hour) }\end{array}$ & -0.13 & 1.01 & $\begin{array}{l}1 \% \\
(3.2 \%)\end{array}$ \\
\hline $\begin{array}{l}1151^{\circ} \mathrm{C} \text { to } 1121^{\circ} \mathrm{C} \\
\text { (1-hour) }\end{array}$ & 0.25 & 1.16 & $\begin{array}{l}16 \% \\
(29.5 \%)\end{array}$ \\
\hline $\begin{array}{l}\text { 1-hour to 24-hour } \\
\left(1121^{\circ} \mathrm{C}\right)\end{array}$ & 0.34 & 1.05 & $\begin{array}{l}5 \% \\
(15.15 \%)\end{array}$ \\
\hline $\begin{array}{l}\text { 24-hour to 1-hour } \\
\left(1121^{\circ} \mathrm{C}\right)\end{array}$ & -0.30 & 1.02 & $\begin{array}{l}2 \% \\
(2.2 \%)\end{array}$ \\
\hline Type II TBC & $\begin{array}{c}\text { Offset between } \\
\text { baseline and } \\
\text { condition B (GPa) }\end{array}$ & $\frac{\text { Predicted Life }}{\text { Actual Failure Life }}$ & $\begin{array}{c}\text { Total Life Error } \\
\text { (Remaining Life } \\
\text { Error) }\end{array}$ \\
\hline $\begin{array}{l}1121^{\circ} \mathrm{C} \text { to } 1151^{\circ} \mathrm{C} \\
\text { (1-hour) }\end{array}$ & -0.53 & 0.99 & $\begin{array}{l}1 \% \\
(2.8 \%)\end{array}$ \\
\hline $\begin{array}{l}1151^{\circ} \mathrm{C} \text { to } 1121^{\circ} \mathrm{C} \\
\text { (1-hour) }\end{array}$ & 0.59 & 1.26 & $\begin{array}{l}26 \% \\
(46.4 \%)\end{array}$ \\
\hline
\end{tabular}




\section{Figure Captions}

Figure 1: Four Layers in Thermal Barrier Coating System

Figure 2: Evolution of TGO stress as a function of TBC life fraction for Type I TBC at $1121^{\circ} \mathrm{C}$ and $1151^{\circ} \mathrm{C}$ for constant and non-constant tests

Figure 3: Evolution of TGO stress as a function of TBC life fraction for Type I TBC for the 1hour and 24-hour constant and non-constant tests

Figure 4: Evolution of TGO stress as a function of TBC life fraction for Type II TBC at $1121^{\circ} \mathrm{C}$ and $1151^{\circ} \mathrm{C}$ for constant and non-constant tests

Figure 5: Schematic of stress offset and transition between condition A and B compared to the baseline curves

Figure 6: Micrograph of 1-hour and 24-hour TBC failure mechanisms 


\section{Figures}

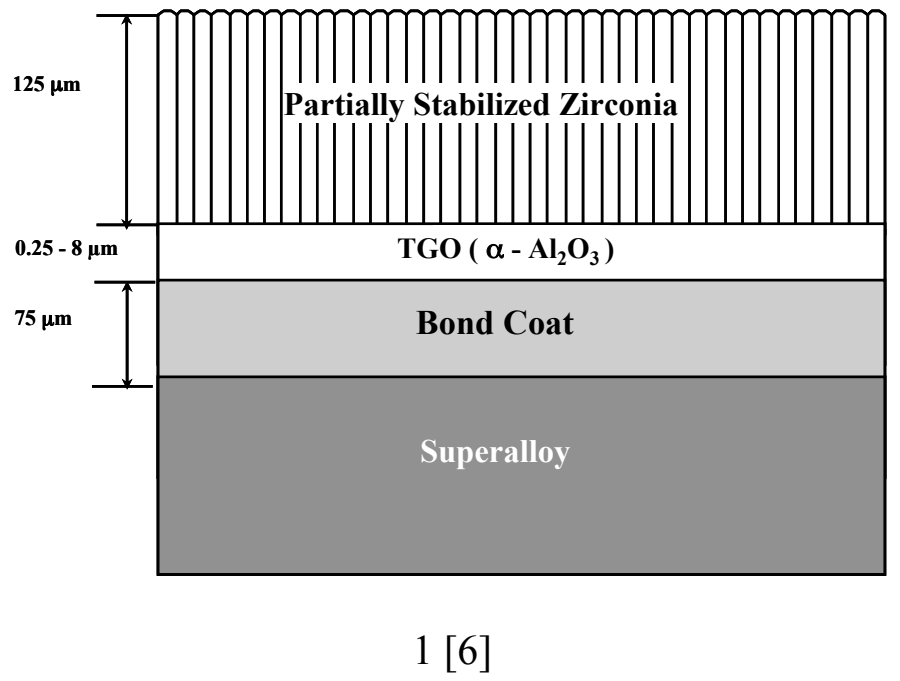




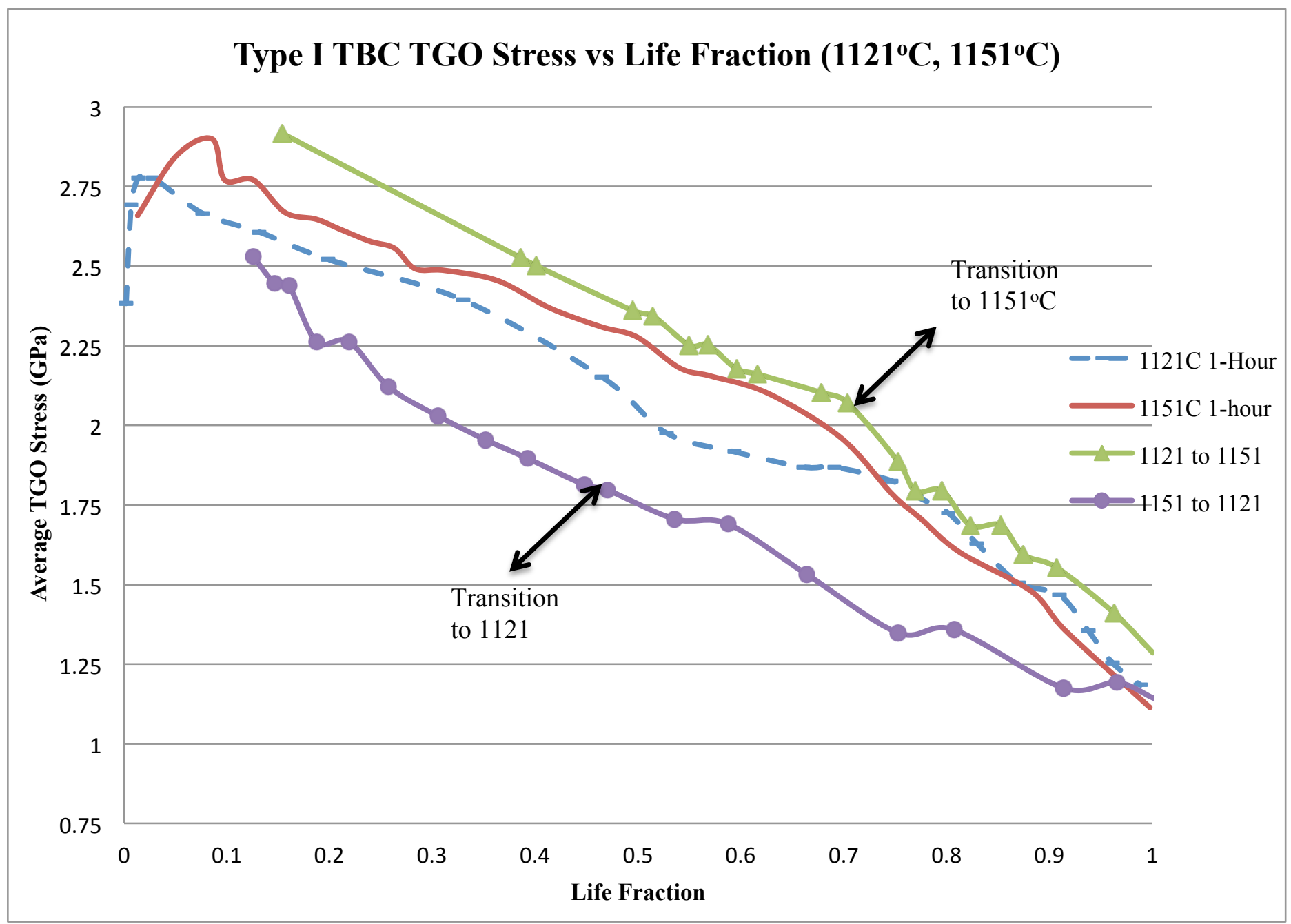




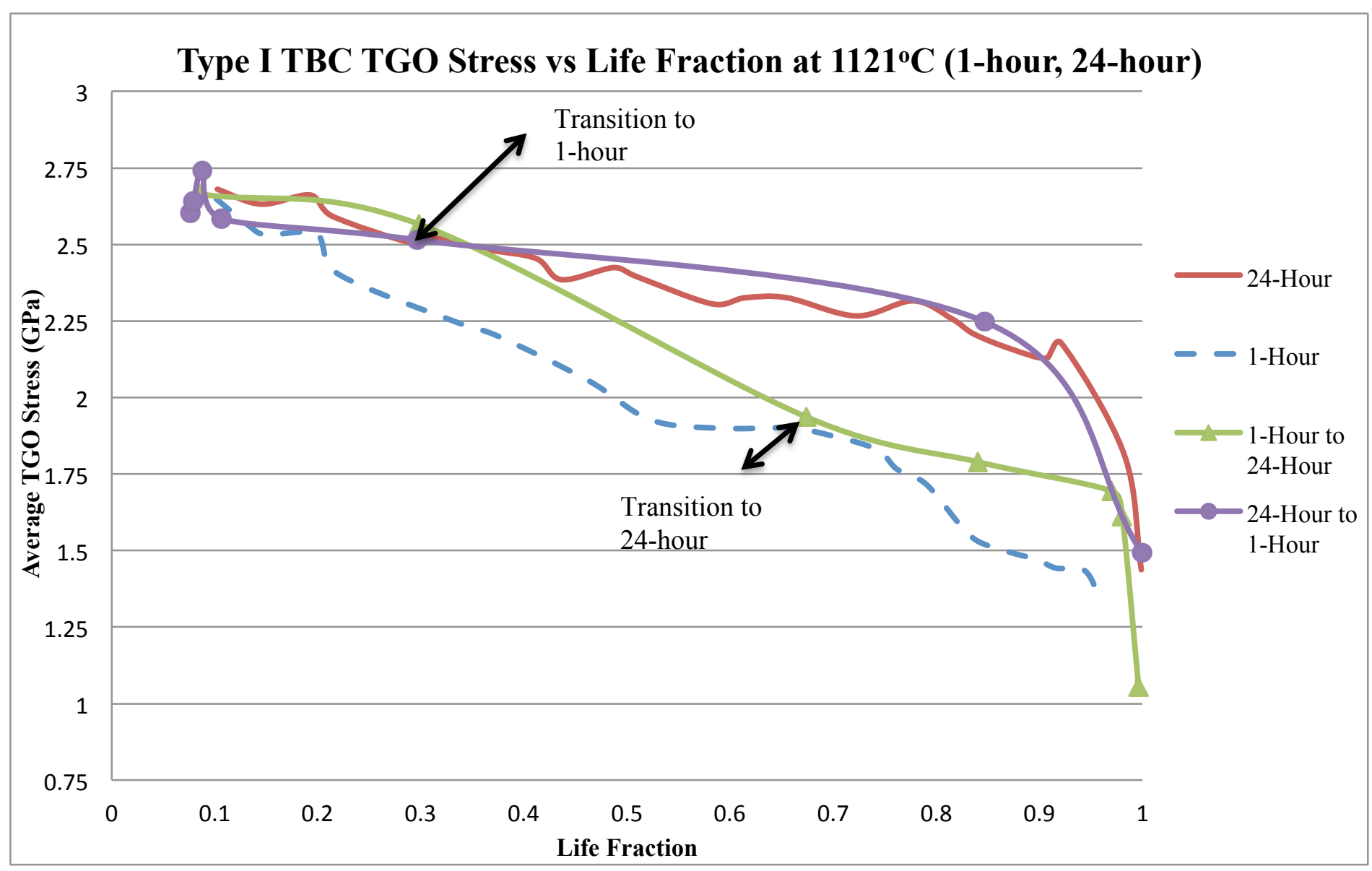




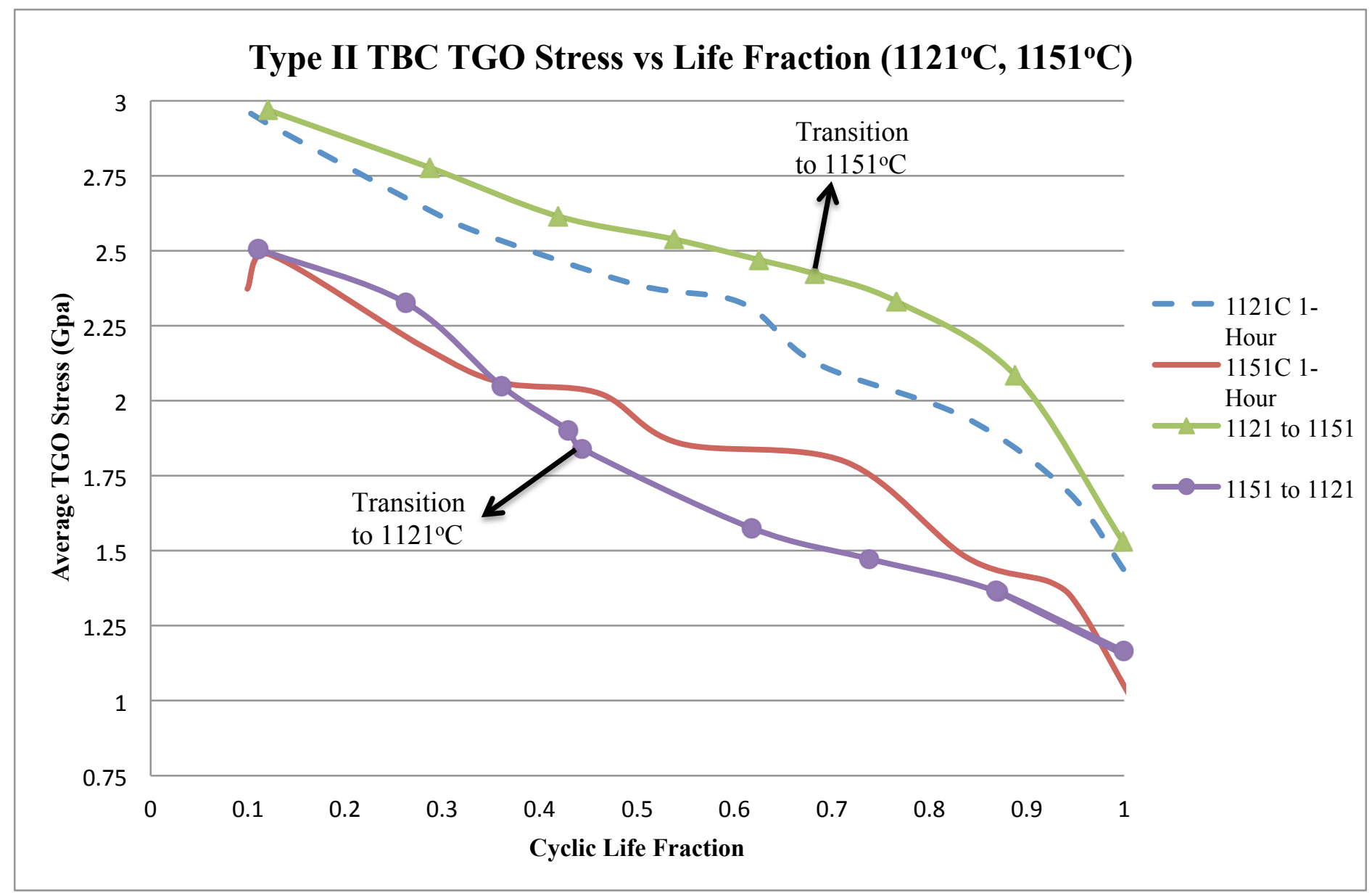




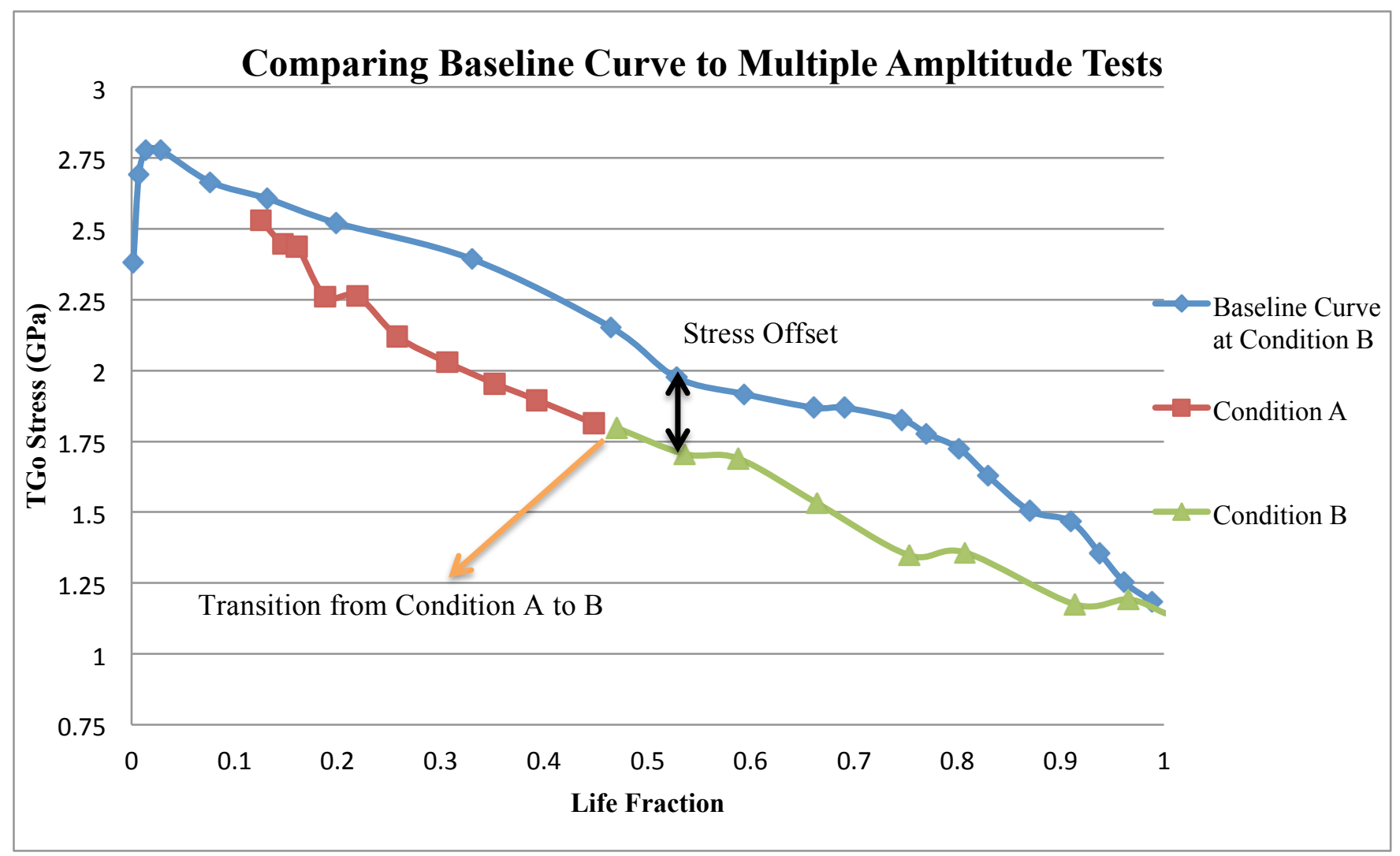

5 


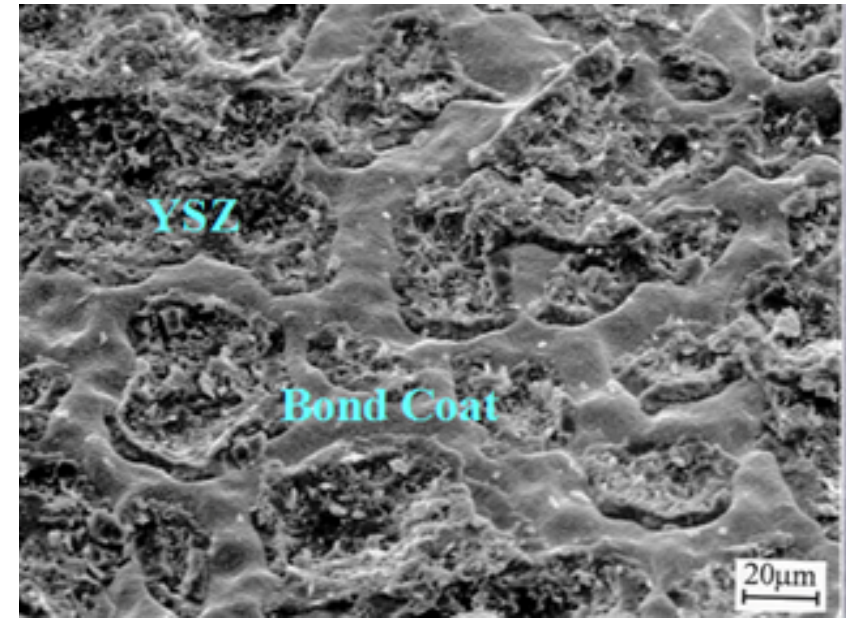

1-hour Test Failure:

Predominately in the YSZ at or near the TBC/TGO Interface

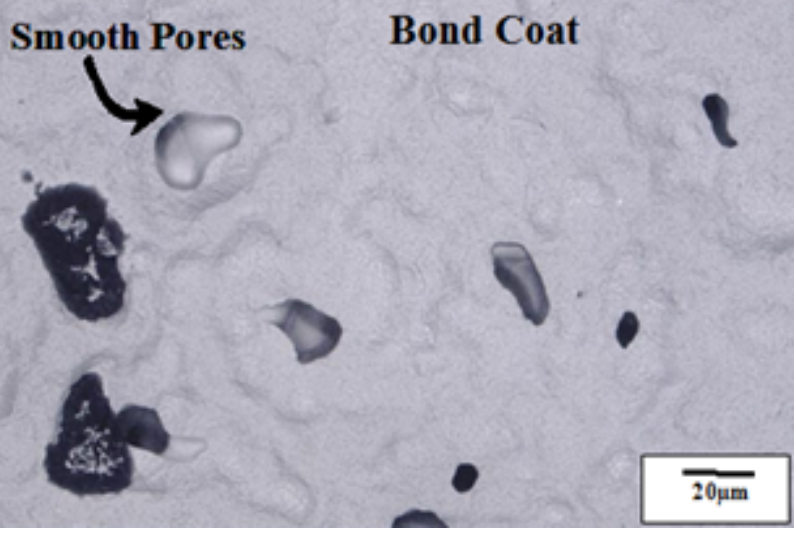

24-hour Test Failure:

Predominately at the TGO/Bond coat interface 